\title{
Bax translocation to mitochondria subsequent to a rapid loss of mitochondrial membrane potential
}

\author{
SS Smaili ${ }^{1,2}$, Y-T Hsu ${ }^{3,4}$, KM Sanders $^{3}$, JT Russell ${ }^{2}$ and \\ RJ Youle Y,3 $^{\text {, }}$ \\ 1 Departamento de Farmacologia, Universidade Federal de São Paulo, Brasil \\ ${ }^{2}$ Laboratory of Cellular and Molecular Neurophysiology, National Institute of \\ Child Health and Human Development, National Institutes of Health, Bethesda, \\ Maryland, MD 20892, USA \\ ${ }^{3}$ Biochemistry Section, Surgical Neurology Branch, National Institute of \\ Neurological Disorders and Stroke, National Institutes of Health, Bethesda, \\ Maryland, MD 20892, USA \\ ${ }^{4}$ Medical University of South Carolina, Charleston, South Carolina, USA \\ * Corresponding author: RJ Youle, Biochemistry Section, Surgical Neurology \\ Branch, National Institute of Neurological Disorders and Stroke, National \\ Institutes of Health, Bethesda, Maryland, MD 20892, USA. \\ Tel: (301) 496-6628; Fax: (301) 402-0380; E-mail: youle@helix.nih.gov
}

Received 13.11.00; revised 12.3.01; accepted 26.3.01

Edited by B Osborne

\begin{abstract}
Bax, a pro-apoptotic member of the Bcl-2 family, is a cytosolic protein that inserts into mitochondrial membranes upon induction of cell death. Using the green fluorescent protein fused to Bax (GFP-Bax) to quantitate mitochondrial binding in living cells we have investigated the cause of Bax association with mitochondria and the time course relative to endogenous and induced changes in mitochondrial membrane potential $\left(\Delta \Psi_{m}\right)$. We have found that staurosporine (STS) induces a loss in $\Delta \Psi_{m}$ before GFP-Bax translocation can be measured. The onset of the $\Delta \Psi_{m}$ loss is followed by a rapid and complete collapse of $\Delta \Psi_{m}$ which is followed by Bax association with mitochondria. The mitochondria uncoupler FCCP, in the presence of the $F_{1}-F_{0}$ ATPase inhibitor oligomycin, can trigger Bax translocation to mitochondria suggesting that when ATP levels are maintained a collapse of $\Delta \Psi_{m}$ induces Bax translocation. Neither FCCP nor oligomycin alone alters Bax location. Bax association with mitochondria is also triggered by inhibitors of the electron transport chain, antimycin and rotenone, compounds that collapse $\Delta \Psi_{m}$ without inducing rapid ATP hydrolysis that typically occurs with uncouplers such as FCCP. Taken together, our results suggest that alterations in mitochondrial energization associated with apoptosis can initiate Bax docking to mitochondria. Cell Death and Differentiation (2001) 8, 909-920.
\end{abstract}

Keywords: mitochondria; Bax; mitochondrial membrane potential; mitochondrial inhibitors

Abbreviations: STS, staurosporine; PTP, permeability transition pore; ANT, adenine nucleotide translocator; TMRE, tetramethylrhodamine ethyl ester; ROI, region of interest; MTR, mito tracker red

\section{Introduction}

Apoptosis is a natural cell elimination process, important during tissue turnover and animal development. Members of the Bcl-2 family are among the first groups of proteins recognized as having the ability to regulate apoptosis. They direct the fate of a cell towards either survival or death by family members having opposing functions, with one class promoting cell survival (Bcl-2, Bcl- $\mathrm{X}_{\mathrm{L}}$ and $\left.\mathrm{Bcl}-\mathrm{w}\right)$ and another promoting cell death (Bax, Bak and Bad). ${ }^{1}$

Bax was first isolated from an IL-3 dependent cell line, FL 5.12, as an antagonist to Bcl-2, having the ability to promote apoptosis upon IL-3 withdrawal. $^{2}$ Bax is found distributed in many tissues of the body ${ }^{3}$ and promotes apoptosis of a wide variety of cell types subjected to death stimuli. $^{1}$ Deletion of Bax results in mice with lymphoid tissue hyperplasia, male sterility, and excess neurons. ${ }^{4,5}$

Overexpression of Bax in mammalian cells promotes cell death that can be blocked by co-expression with prosurvival factors $\mathrm{Bcl}-2$ and $\mathrm{BCL}-\mathrm{X}_{\mathrm{L}} \cdot{ }^{6-8}$ Like many other $\mathrm{Bcl}-2$ family members, Bax has three conserved regions known as the $\mathrm{BH} 1, \mathrm{BH} 2$ and $\mathrm{BH} 3$ domains, ${ }^{8,9}$ and a predicted membrane-spanning domain at its carboxyl terminal end. ${ }^{2}$ Studies have shown that the $\mathrm{BH} 3$ region and the $\mathrm{C}$-terminal tail of Bax appear to be the crucial domains required for its pro-apoptotic function. ${ }^{8,10}$ Bax has been reported to be predominantly a soluble cytosolic protein despite the presence of its C-terminal hydrophobic segment. ${ }^{11}$ Upon induction of apoptosis, however, Bax translocates from the cytosol to mitochondrial membranes. ${ }^{10,11}$ Modulating this membrane insertion step can regulate apoptosis. ${ }^{12-14}$ In addition, Bax can induce mitochondrial-independent mechanisms during cell death. ${ }^{15}$

Induction of apoptosis leads to the loss of $\Delta \Psi_{\mathrm{m}}{ }^{16}$ mitochondrial dysfunction ${ }^{17}$ and release of caspase 9 , AIF and cytochrome $c .^{18-21}$ While some of these studies show that the collapse of $\Delta \Psi_{\mathrm{m}}$ is associated with cytochrome $c$ release, ${ }^{16,22-25}$ others show that cytochrome $c$ release is an early event that precedes $\Delta \Psi_{\mathrm{m}}$ dissipation. ${ }^{26}$ Goldstein et al. show that the cytochrome $c$ release is rapid, complete and occurs without $\Delta \Psi_{\mathrm{m}}$ loss. ${ }^{27}$ It has also been reported that the addition of recombinant Bax to intact mitochondria can disrupt the mitochondrial outer membrane to promote the release of cytochrome $c .^{28}$ In addition, overexpression of Bax in transfected cultured cells appears to induce the loss of $\Delta \Psi_{\mathrm{m}}$ and activation of caspase-3.,29

Changes in $\Delta \Psi_{\mathrm{m}}$ during apoptosis induction have been attributed to the opening of the mitochondrial permeability transition pore (PTP). ${ }^{25,29,30}$ Although the molecular identity of the PTP is currently unclear, it is well known that the pore is a protein complex with components including cyclophylin D, adenine nucleotide translocator (ANT), VDAC and others. ${ }^{31}$ Opening of the pore leads to the 
release of calcium and a variety of solutes with molecular mass up to 1500 Daltons. $^{32}$ It has been reported that Baxinduced cytochrome $c$ release occurs by its interaction with ANT, opening of PTP and decrease in the $\Delta \Psi_{\mathrm{m}}$. On the other hand, other findings indicate that cytochrome $c$ release can be independent of $\Delta \Psi_{\mathrm{m}}$ loss $^{26,27}$ and under certain circumstances independent of PTP, ${ }^{33}$ occurring via PTP insensitive pathways. ${ }^{34}$ Recent findings have shown that Bax-induced cytochrome $c$ release occurs through an interaction with mitochondria contact sites, without mitochondrial rupture and independent of PTP. ${ }^{26,35}$ Therefore, it remains unclear whether or not Bax induces cytochrome $c$ release through permeability transition or other mechanisms independent of PTP or both.

Another mechanism associated with Bax toxicity is related to its capability of forming membrane channels or pores. $^{36}$ Bax homodimers, heterodimers and oligomers have been found in the presence of detergents, ${ }^{37,38}$ suggesting that the membrane intercalated form of Bax may form larger complexes. Recent findings have shown that Bax-formed pores may lead to disruption of the mitochondrial membrane. ${ }^{39-41}$

Studies using mitochondrial inhibitors have shown that respiration may or may not be involved in apoptosis. Inhibitors of the respiratory chain can cause PTP opening and caspase activation and induce apoptotic cell death. ${ }^{42-45}$ However, it has been suggested that respiration is not required during apoptosis in yeast and in some mammalian cells. ${ }^{46}$ On the other hand, ATP and ATP synthesis are important requirements for apoptosis. ${ }^{25,47}$ Recent findings show that Bax toxicity is increased in cells more dependent on oxidative phosphorylation. ${ }^{48}$

It has not been established what triggers Bax translocation to mitochondria and how this mechanism may depend on $\Delta \Psi_{\mathrm{m}}$ or mitochondrial energy. One report has suggested that increased cytosolic $\mathrm{pH}$ may trigger Bax insertion. ${ }^{49}$ However, recent findings have shown that Bax induces an increase in mitochondrial and a decrease in cytosolic $\mathrm{pH}$ that precedes cytochrome $c$ release and caspase activation. $^{50}$

In this report, we examine the sequential order and interrelationships between Bax translocation to mitochondria and the loss of $\Delta \Psi_{\mathrm{m}}$ and the role of Bax translocation with respect to mitochondrial dysfunction, inhibition of the respiratory chain, activation of PTP as well as the role of the mitochondrial ATPase activity during this process.

\section{Results}

\section{The loss of mitochondrial membrane potential precedes detection of GFP-Bax association with mitochondria}

In order to determine the sequential order of $\Delta \Psi_{\mathrm{m}}$ loss relative to Bax translocation from the cytosol to mitochondria, we transfected GFP-Bax into Cos-7 cells and incubated the cells with the membrane potential sensitive dye, TMRE. TMRE is a rhodamine derivative dye that is cell-permeant and is readily sequestered by energized mitochondria without inducing cytotoxic effects. ${ }^{51}$ The accumulation of TMRE in mitochon- dria is driven by $\Delta \Psi_{m}$ and is a sensitive method to measure changes in $\Delta \Psi_{\mathrm{m}}{ }^{52}$ This compound, as other cationic dyes, has been used to measure changes in $\Delta \Psi_{\mathrm{m}}$ upon induction of apoptosis by a variety of stimuli. ${ }^{17}$ Tetramethylrhodamine dyes such as TMRE are advantageous for this, since in the low nanomolar range the rhodamine group stains mainly mitochondria and is not retained by the cell upon $\Delta \Psi_{\mathrm{m}}$ collapse as is MitoTracker Red. ${ }^{53}$

We treated Cos-7 cells transfected with GFP-Bax and labeled with TMRE with $1 \mu \mathrm{M}$ staurosporine and followed Bax translocation into mitochondria and changes in $\Delta \Psi_{\mathrm{m}}$ simultaneously over time with a CCD camera. Figure 1 shows a typical experiment where a cell transfected with GFP-Bax (top) is exposed to staurosporine. GFP-Bax, which initially displayed a diffuse fluorescence pattern consistent with a cytosolic localization, inserted into mitochondria upon induction of apoptosis by staurosporine. TMRE fluorescence was recorded simultaneously in the same cell (bottom). Immediately after the complete collapse of $\Delta \Psi_{\mathrm{m}}$, GFP-Bax migration into the mitochondria could be detected as an increase in GFP fluorescence in the mitochondria. In the same field, other cells not transfected with GFP-Bax were used as controls to monitor the TMRE decay associated with translocation of native levels of Bax.

Changes in TMRE and GFP fluorescence within individual mitochondria were quantitatively analyzed as described in Materials and Methods. Mitochondria were selected from regions of the cell where elongated individual mitochondria could be distinguished. Normalized fluorescence intensity within each region of interest (ROI) was plotted against time and the loss of $\Delta \Psi_{\mathrm{m}}$ (decrease in TMRE fluorescence) was compared with the onset of GFPBax translocation (increase in GFP fluorescence) in the same mitochondria. Figure 2 shows results from three different mitochondria, representative of three different patterns of dynamic changes that were observed. ROls were chosen in GFP-Bax expressing cells. Examples of one ROI in the cell periphery (mitochondrion 1) and two in perinuclear areas (mitochondria 2 and 3) are shown in Figure 2A. As shown in Figure 2B, the collapse of $\Delta \Psi_{\mathrm{m}}$ (black trace) progressed rapidly. On average collapse of $\Delta \Psi_{\mathrm{m}}$ took $3 \mathrm{~min}$ for mitochondria in the periphery of cells and $17 \mathrm{~min}$ for mitochondria in the perinuclear region. In contrast, in the same ROIs, GFP-Bax fluorescence increased and reached a plateau within a span of 20$40 \mathrm{~min}$ (red trace). Mitochondria from cells not expressing GFP-Bax maintained their $\Delta \Psi_{\mathrm{m}}$ over this time period (for example see mitochondria 4 and 5). In every case, accumulation of GFP-Bax into mitochondria occurred at least after more than $50 \%$ dissipation of $\Delta \Psi_{\mathrm{m}}$ had occurred. Similar results were obtained in 277 individual mitochondria examined in different cells from five individual experiments. The time at which the changes in $\Delta \Psi_{m}$ and GFP-Bax accumulation began and the time when GFP-Bax translocation reached a plateau were measured to quantitatively analyze the temporal sequence. Figure 2C shows a histogram of the times at which $\Delta \Psi_{\mathrm{m}}$ collapsed and the GFP-Bax migration was complete. This analysis confirmed that measurable GFP-Bax translocation appeared on average minutes after the complete collapse of $\Delta \Psi_{\mathrm{m}}$. 

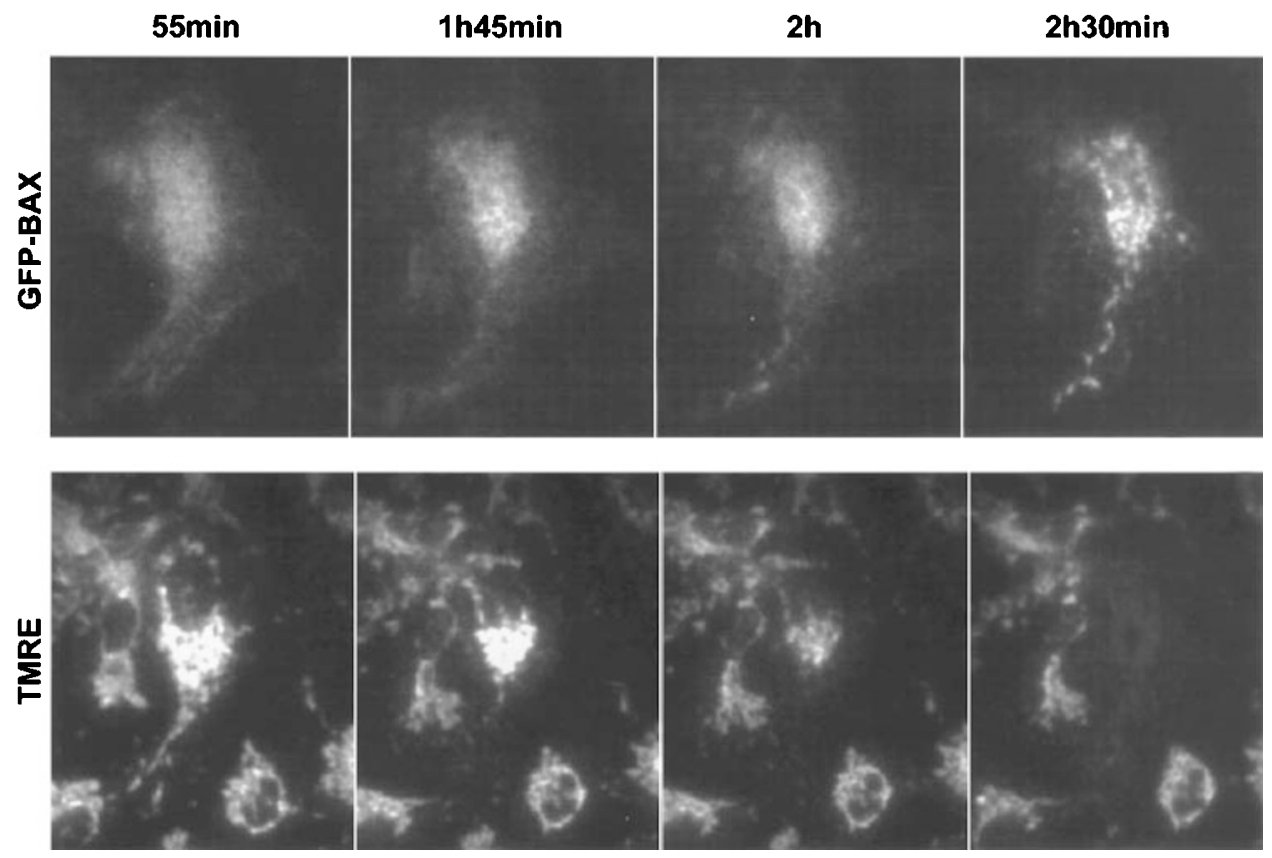

Figure 1 Staurosporine induces the loss of mitochondrial membrane potential $\left(\Delta \Psi_{m}\right)$ prior to GFP-Bax translocation. A healthy Cos-7 cell expressing GFP-Bax was stained with TMRE for $\Delta \Psi_{m}$ visualization. The GFP-Bax (top row) and TMRE (bottom row) fluorescence patterns of the cell were simultaneously monitored over time (shown on the top) with a CCD camera after the addition of $1 \mu \mathrm{M}$ staurosporine. The loss of $\Delta \Psi_{\mathrm{m}}$ appears to occur prior to Bax translocation into the mitochondria. Images are representative of at least seven individual experiments and 12 transfected cells

Overexpression of Bax promotes the loss of $\Delta \Psi_{\mathrm{m}} \cdot{ }^{29,30,54,55}$ Similarly, in our study we found that whereas the mitochondria from transfected cells exposed to staurosporine lost their electrochemical potential, the $\Delta \Psi_{\mathrm{m}}$ from surrounding untransfected cells (for example see cells on left, Figure 1) showed little change within the time frame examined.

Data obtained from all the measurements (277 mitochondria from five experiments) are summarized in Table 1. The loss of $\Delta \Psi_{\mathrm{m}}$, once initiated, is rapid and is complete in $17 \pm 0.6 \mathrm{~min}$. GFP-Bax translocation into mitochondria then starts an average of $8.2 \pm 1.4 \mathrm{~min}$ after the collapse of $\Delta \Psi_{\mathrm{m}}$. The kinetics of GFP-Bax translocation, in contrast to the time course of $\Delta \Psi_{\mathrm{m}}$ loss, is a slower process and takes $48.9 \pm 1.1 \mathrm{~min}$ to complete. Although the collapse of $\Delta \Psi_{\mathrm{m}}$ in peripheral mitochondria and perinuclear mitochondria occurred at different times, the rate at which the loss of $\Delta \Psi_{\mathrm{m}}$ occurred is similar in both populations. In $17 \%$ of the mitochondria obtained from 26 different cells, some photobleaching was observed and mitochondria that showed a constant and slow decrease in TMRE fluorescence from the beginning of the experiment were discarded from analysis.

\section{The loss of $\Delta \Psi_{m}$ triggers Bax translocation when the mitochondrial ATPase and ATP consumption are inhibited}

The finding that the loss of $\Delta \Psi_{\mathrm{m}}$ precedes detectable Bax association with mitochondria prompted us to investigate whether the loss of mitochondrial potential could be a trigger for Bax translocation. Cos-7 cells expressing GFP-Bax were treated with the protonophore FCCP $(5 \mu \mathrm{M})$ in the absence of STS, and the TMRE and GFP-Bax fluorescence patterns were monitored by a CCD camera and by confocal microscopy. As shown in Figure 3A, after addition of FCCP, $\Delta \Psi_{\mathrm{m}}$ dissipates completely in 2-3 min. However, over a period of $2-3 \mathrm{~h}$ after the FCCP-induced loss in $\Delta \Psi_{\mathrm{m}}$, no translocation of Bax was detected. This rules out the possibility that the loss of $\Delta \Psi_{\mathrm{m}}$ itself, triggers Bax translocation. As FCCP induces a collapse of the $\Delta \Psi_{\mathrm{m}}$ we investigated Bax translocation in the presence of MitoTracker Red (MTR). MTR is accumulated by energized mitochondria in response to $\Delta \Psi_{\mathrm{m}}$ and is bound to mitochondrial sulfhydryl (SH) groups. This covalent linkage to the matrix and membrane $\mathrm{SH}$ groups prevent MTR from being completely released from mitochondria during the loss of $\Delta \Psi_{\mathrm{m}}{ }^{53}$ In our studies we found only a small amount of MTR was released to the cytosol after FCCP addition, and $3 \mathrm{~h}$ or more after the addition of STS, GFP-Bax association with mitochondria was not detectable (Figure 3B).

Proton ionophores are highly effective in depleting cellular ATP. The lowered $\Delta \Psi_{\mathrm{m}}$ results in the rapid hydrolysis of cytoplasmic ATP by the mitochondrial ATP synthase. $^{56}$ As ATP depletion is reported to block apoptosis, we investigated whether FCCP would affect Bax translocation in the presence of oligomycin $(2 \mu \mathrm{g} / \mathrm{ml})$, a mitochondrial ATP synthase (ATPase) inhibitor that efficiently maintains the ATP/ADP ratio during FCCP exposure. ${ }^{56,57}$ In some experiments, MTR was used instead of TMRE to monitor mitochondria location. In contrast to FCCP alone (Figure 3), significant Bax binding to mitochondria was observed in less than $2 \mathrm{~h}$ after cell treatment with FCCP plus oligomycin (Figure 4). As expected, oligomycin alone did not induce the collapse of 


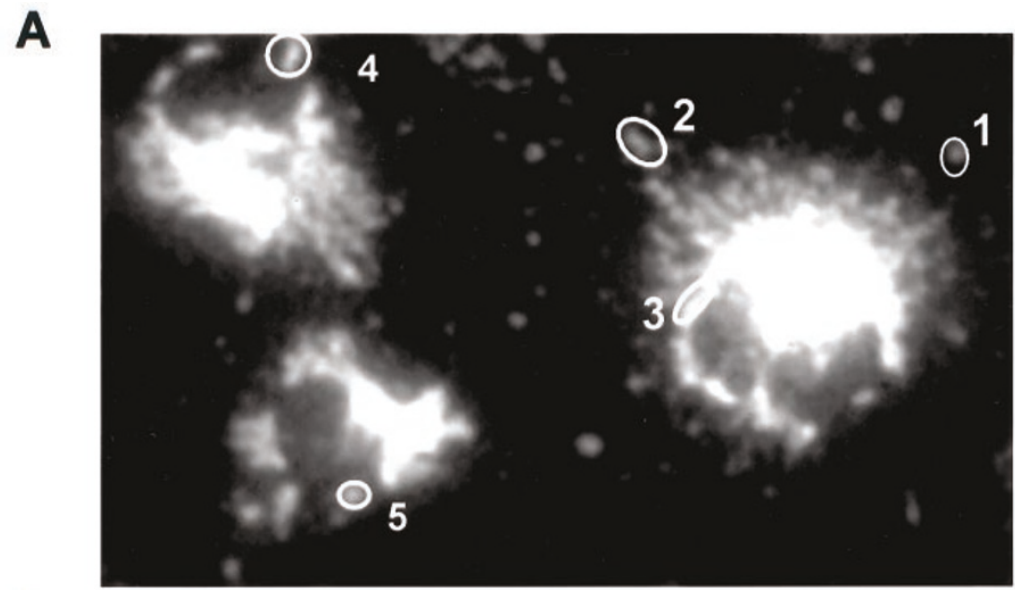

B
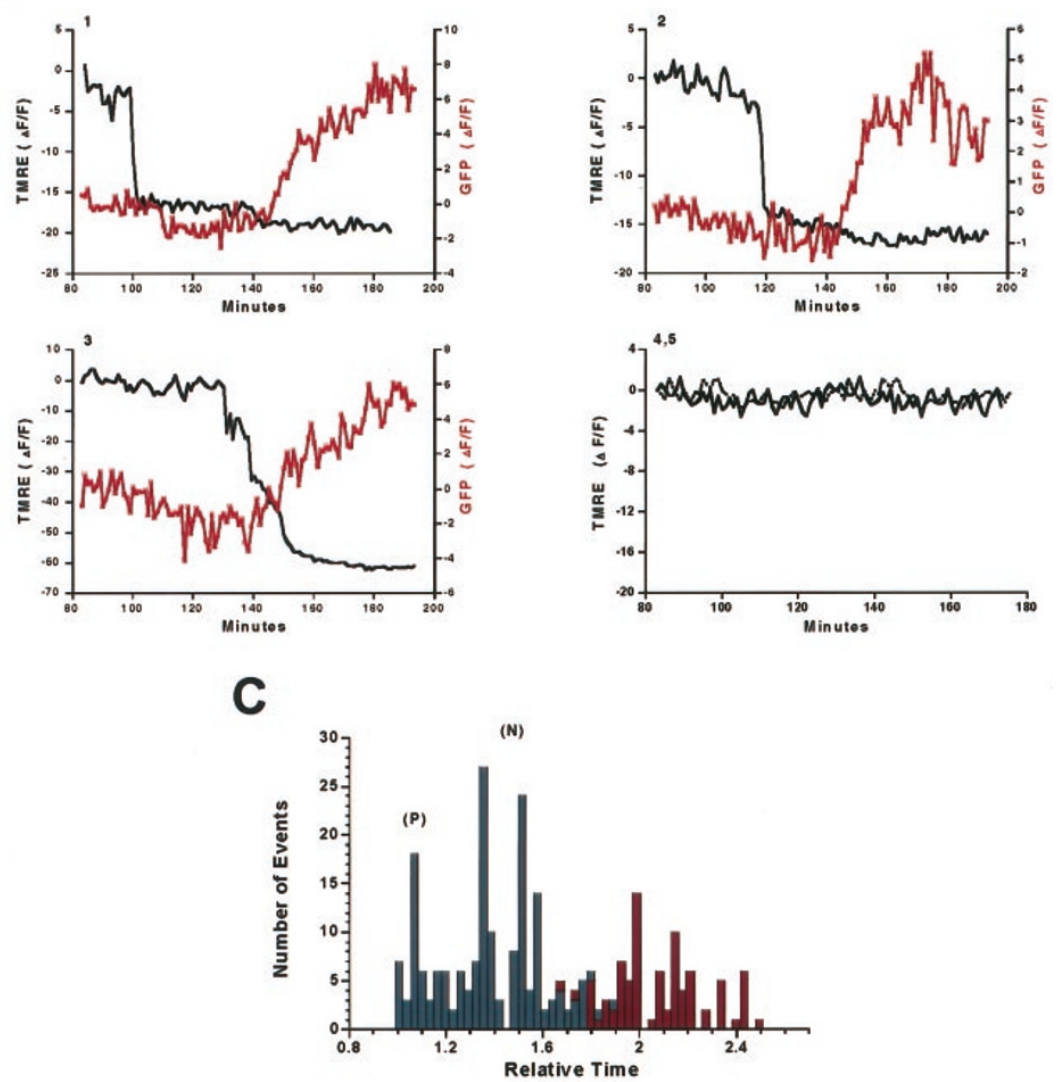

Figure 2 Quantitative analysis of changes in mitochondrial membrane potential $\left(\Delta \Psi_{\mathrm{m}}\right)$ relative to GFP-Bax association with mitochondria. (A) Arbitrarily chosen mitochondrial regions of interest (ROIs) found in a GFP-Bax expressing Cos-7 cells were delimited and analyzed individually for changes in their TMRE and GFPBax fluorescence. (B) Representative graphical analyses of changes in TMRE compared with GFP-Bax fluorescence within the same region of the mitochondrial boundaries. Fluorescence intensities within each ROI (1-5) were averaged $(F)$ and plotted as normalized fluorescence intensities $\left(\Delta F / F_{0}\right)$ against time, where $\Delta F$ was calculated as the difference between $F$ and $F_{0} . F_{0}$ is the mean basal fluorescence value obtained from averaging the first 20 data points. Panels $1-3$ show three examples of individual mitochondrion where the loss of $\Delta \Psi_{m}$ occurs prior to GFP-Bax translocation into mitochondria. Responses showed different patterns of dynamic changes that were averaged in Table 1. Panels 4 and 5 show mitochondria from GFP-Bax non-expressing control cells that maintained their $\Delta \Psi_{\mathrm{m}}$ over time. (C) Histogram showing the relative times (measured in minutes) at which $\Delta \Psi_{m}$ was observed (gray bars) and GFP-Bax association (red bars) occurred in individual mitochondria. Number of mitochondria ( $Y$-axis) showing changes are plotted against the time at which the fluorescence change is complete. Time scale (X-axis) is normalized in each cell to the earliest organelle showing change in $\Delta \Psi_{\mathrm{m}}$. Since the onset of staurosporine-induced cell death occurred at different times after addition of staurosporine, measurements in different cells were thus normalized for comparison. Note that in one population of mitochondria, mostly in the periphery of the cell $(\mathrm{P})$, the collapse of $\Delta \Psi_{\mathrm{m}}$ occurs earlier than in those located in the perinuclear (N) region. GFP-Bax translocation into mitochondria occurs minutes after the loss in $\Delta \Psi_{m}$ is complete and occurs only in $45 \%$ of the mitochondria visualized with TMRE staining in the beginning of the experiment 
Table 1 Average time (in minutes) for the collapse of $\Delta \Psi_{\mathrm{m}}$ and the delay between $\Delta \Psi_{\mathrm{m}}$ loss and the start (Bs) and completion $(\mathrm{Bc})$ of GFP-Bax translocation to mitochondria

\begin{tabular}{lccc}
\hline $\begin{array}{l}\text { Total number of } \\
\text { mitochondria }\end{array}$ & $\Delta \Psi_{\mathrm{m}}$ loss & $\begin{array}{c}\text { Time after } \\
\Delta \Psi_{\mathbf{m}} \text { loss for } \\
\text { GFP-Bax (Bs) }\end{array}$ & $\begin{array}{c}\text { Time after } \\
\Delta \Psi_{\mathbf{m}} \text { loss for } \\
\text { GFP-Bax (Bc) }\end{array}$ \\
\hline 277 & $17.7 \pm 0.6$ & $8.2 \pm 1.4$ & $48.9 \pm 1.1$ \\
\hline
\end{tabular}

All values are in mean \pm S.E.M. Two hundred and seventy-seven ROls or mitochondria were analyzed from five individual experiments. $\Delta \Psi_{\mathrm{m}}$ loss is the time taken for the complete loss of $\Delta \Psi_{\mathrm{m}}$ once it was initiated; Bs is the delay between the complete loss of $\Delta \Psi_{m}$ and the onset of GFP-Bax association with mitochondria; $\mathrm{Bc}$ indicates the delay between the complete loss of $\Delta \Psi_{\mathrm{m}}$ and the completion of GFP-Bax translocation

the $\Delta \Psi_{\mathrm{m}}$, and was not able to induce Bax translocation to mitochondria (data not shown). These experiments were performed in 10 different cells from at least six different experiments.

\section{Mitochondrial inhibitors promote Bax translocation into mitochondria}

The mitochondrial inhibitors of the electron transport chain (ETC), rotenone and antimycin increase expression of apoptosis markers and lead to cell death. ${ }^{44}$ Since the ETC maintains $\Delta \Psi_{\mathrm{m}}$, we investigated the possible involvement of the electron transport chain in regulating Bax translocation.

We examined the effect of ETC inhibitors in GFP-Bax expressing Cos-7. The percentage of cells with Baxassociated mitochondria was then quantitated. Cells were examined at 0 and $6 \mathrm{~h}$ after treatment with FCCP, FCCP plus oligomycin, oligomycin, antimycin or rotenone. STS, a standard compound used in our studies to induce GFP-Bax translocation and insertion into mitochondria, ${ }^{10,11}$ was used for comparison. Figure $5 \mathrm{~A}$ shows that upon treatment with FCCP or oligomycin alone, the percentage of cells with Bax associated with mitochondria at $6 \mathrm{~h}$ was not significantly different from that at $0 \mathrm{~h}$. However, when cells were treated with FCCP plus oligomycin, the percentage of cells with mitochondrial Bax increased from $20-62 \%$, corroborating the results obtained in Figure 4. Mitochondrial ETC inhibitors of complexes I (rotenone) and III (antimycin) caused, respectively, a 40 and $25 \%$ increase in Bax association with mitochondria after $6 \mathrm{~h}$ of treatment.

In another set of experiments (Figure 5B), a similar study was carried out in GFP-Bax transfected L929 cells. Enhanced Bax association with mitochondria was observed in cells treated with FCCP plus oligomycin after $6 \mathrm{~h}$, with a slight increase after $12 \mathrm{~h}$. In contrast, after $6 \mathrm{~h}$ of treatment with STS $(1 \mu \mathrm{M})$, the percentage of cells with punctate GFP-Bax was somewhat higher (85\%) than with the mitochondrial inhibitors (Figure 5C). Since FCCP collapses $\Delta \Psi_{\mathrm{m}}$ and releases mitochondrial $\mathrm{Ca}^{2+32}$ one could postulate that higher concentrations of $\mathrm{Ca}^{2+}$ released to the cytosol could be a trigger for Bax translocation to mitochondria. In order to test this possibility, we loaded the cells with BAPTA-AM $(10 \mu \mathrm{M})$, a calcium chelator, for 30 min before the treatment with FCCP plus oligomycin, or STS. As shown in Figure $5 \mathrm{C}$, the chelation of intracellular
$\mathrm{Ca}^{2+}$ did not prevent STS or FCCP plus oligomycin-induced Bax translocation to mitochondria. In fact, in the presence of FCCP plus oligomycin, BAPTA increased Bax association with mitochondria.

We then examined the roles of FCCP and oligomycin on cell death. Healthy Cos-7 cells were treated with FCCP or FCCP plus oligomycin and analyzed with the nuclear Hoechst stain to check the extent of cell death. FCCP itself did not induce significant levels of apoptosis after 6, 12 or $24 \mathrm{~h}$ treatment (Figure 6). On the other hand, FCCP plus oligomycin caused a significant increase in the number of apoptotic cell deaths (Figure 6). Oligomycin alone did not cause significant cell death (data not shown).

\section{Discussion}

Bax is a pro-apoptotic member of the Bcl-2 family that plays important roles in such diverse physiological events as spermatogenesis, anti-viral defense, and tumorigenesis. Although it possesses a potential transmembrane domain like most members of the Bcl-2 family, Bax in healthy living cells is found to reside predominantly in the cytosol and migrates from the cytosol into organelle membranes during apoptosis. ${ }^{10,11,13}$ Overexpression of Bax in cultured cells is associated with the loss of mitochondrial membrane potential and the activation of caspase-3..$^{7,29,55}$ In this report, we show that the loss of $\Delta \Psi_{\mathrm{m}}$ precedes the bulk of Bax translocation into mitochondria and that the translocation of Bax can be stimulated by $\Delta \Psi_{\mathrm{m}}$ loss if ATP levels are maintained. We show that the onset of $\Delta \Psi_{\mathrm{m}}$ loss is followed by a rapid and dramatic collapse of $\Delta \Psi_{\mathrm{m}}$. This phenomenon precedes the initiation of GFP-Bax association with mitochondria by $8.2 \mathrm{~min}$ on average suggesting that the decrease in $\Delta \Psi_{\mathrm{m}}$ is a trigger for Bax translocation. Collapse of $\Delta \Psi_{\mathrm{m}}$ typically occurs during apoptosis and has been proposed to be an essential step prior to caspase activation and cell death. ${ }^{19}$

Recent findings have shown that cytochrome $c$ release is rapid and once initiated is complete in $5 \mathrm{~min}$ and occurs without any change in $\Delta \Psi_{\mathrm{m} \cdot{ }^{27}}$ Some reports suggest that the release of cytochrome $c$ occurs prior to detectable changes in $\Delta \Psi_{\mathrm{m}} \cdot{ }^{26,58}$ On the other hand, others have shown that cytochrome $c$ release occurs during $\Delta \Psi_{\mathrm{m}}$ collapse. ${ }^{24}$ However, these studies were not performed in a Baxoverexpressing system. Overexpression of Bax promotes the loss of $\Delta \Psi_{m} \cdot{ }^{29,30,55}$ Bax can have direct membrane permeation activity ${ }^{36,39}$ and can cause release of cytochrome $c .^{28}$ Thus, it has been proposed that Bax insertion into mitochondria may initiate or mediate cytochrome $c$ release and/or the loss of $\Delta \Psi_{\mathrm{m}}$. It is surprising therefore that we find that the loss of $\Delta \Psi_{\mathrm{m}}$ actually precedes Bax translocation. Although cytochrome $c$ release occurs close in time to $\Delta \Psi_{\mathrm{m}}$ loss and collapse ${ }^{24}$ it is still uncertain whether the release occurs before, during or after $\Delta \Psi_{\mathrm{m}}$ loss. Two different studies using similar methodology showed that cytochrome $c$ release occurs either before ${ }^{27}$ or during $\Delta \Psi_{\mathrm{m}}$ collapse. ${ }^{24}$ These differences may be a consequence of the different cells used and different apoptotic stimuli, which also varied from the present work. Certainly, further studies using different systems and inducers will be required to clarify controversial findings. 
A
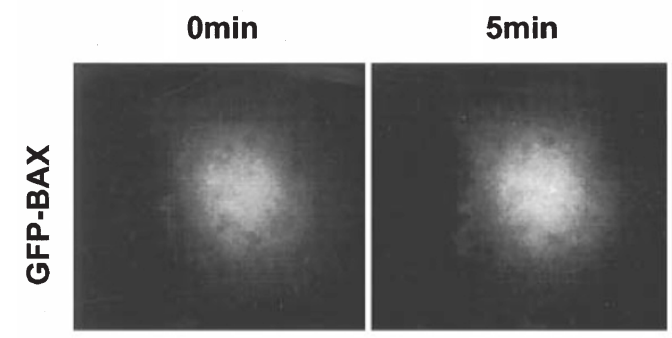

$1 \mathrm{~h}$

2h
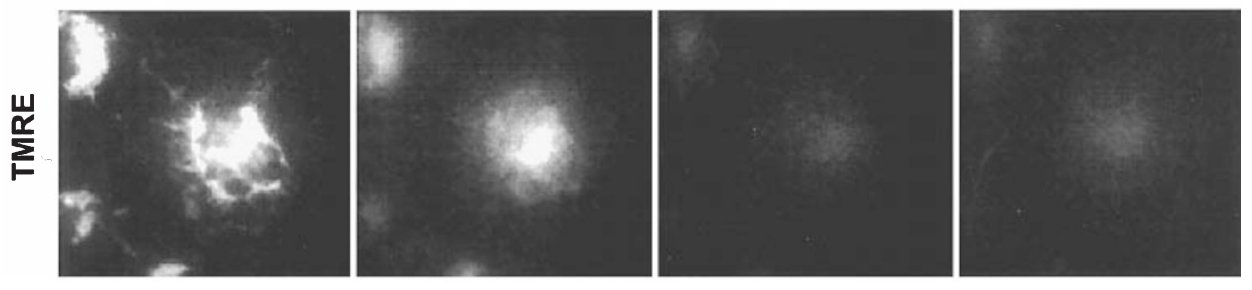

B
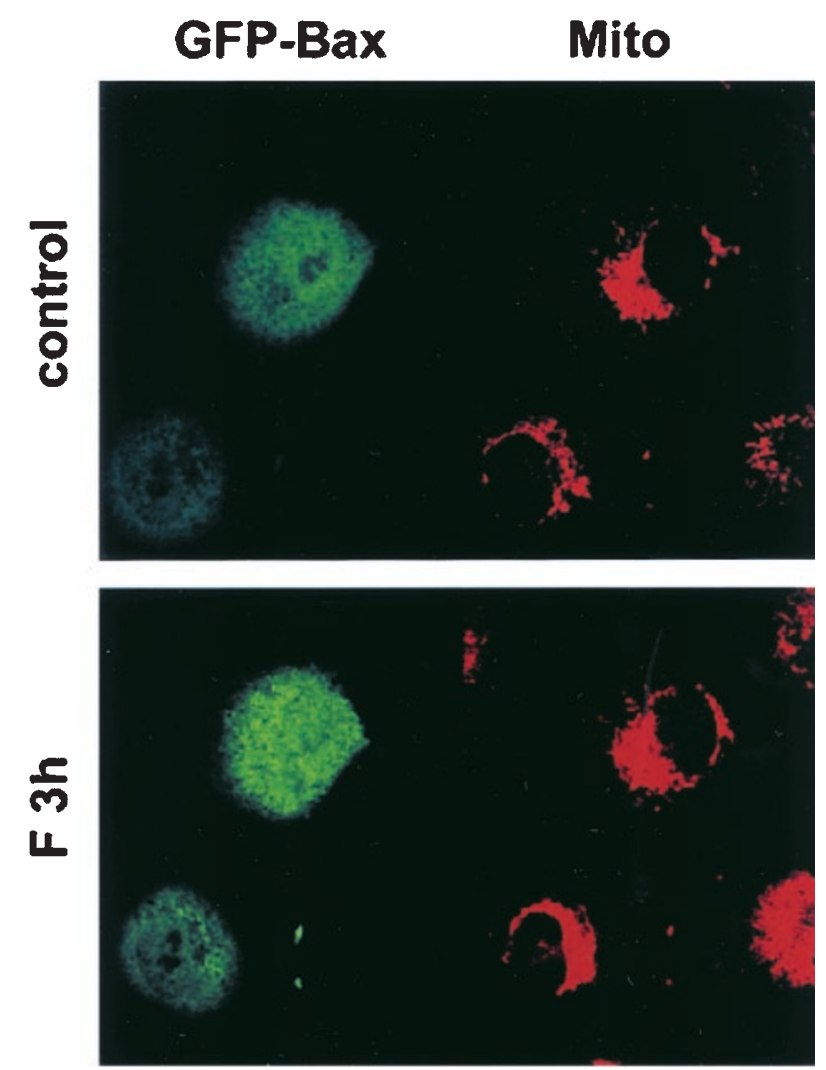

Figure 3 Dissipation of $\Delta \Psi_{m}$ by FCCP does not induce Bax translocation into mitochondria. (A) Cos-7 cell transiently transfected with GFP-Bax was loaded with the TMRE dye. The changes in GFP-Bax (top row) and TMRE (bottom row) fluorescence patterns were monitored over time with a CCD camera. The $\triangle \Psi_{m}$ was then disrupted with the protonophore FCCP. The loss in $\triangle \Psi_{m}$ was complete within 2-5 min after the addition of FCCP, but no change in the cytosilic localization of GFPBax was observed more than $2 \mathrm{~h}$ after the addition of FCCP. Similar results were obtained from three individual experiments. (B) The same experiment was performed using confocal microscopy to visualize cells transfected with GFP-Bax and loaded with Mitotracker Red (MTR) to monitor mitochondria location. Bax translocation was not induced under these conditions

A small amount of GFP-Bax, below the level of detection, could insert into mitochondria prior to the decrease in $\Delta \Psi_{\mathrm{m}}$. Our previous studies have shown that Bax resides primarily in the cytosol with a small proportion
$(<20 \%)$ in the membranes. ${ }^{11}$ Assuming this equilibrium is maintained in a Bax overexpression system such as that of the GFP-Bax expressing Cos-7 cells (estimated to be $3-5$ times the endogenous Bax level), the total amount of the 

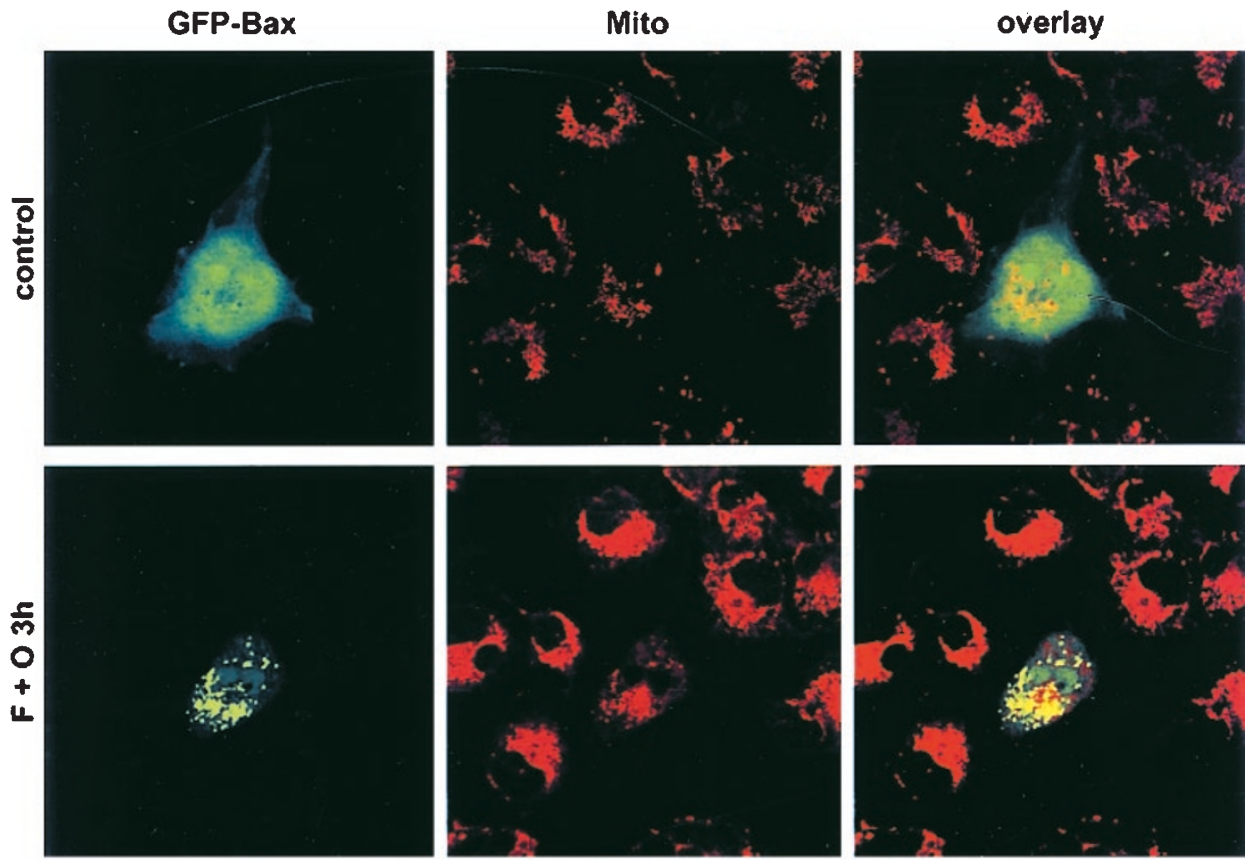

Figure 4 Dissipation of $\Delta \Psi_{m}$ by FCCP in the presence of oligomycin allows Bax association with mitochondria. Cos-7 cells transfected with GFP-Bax were loaded with the MitoTracker Red (MTR) dye. Changes in MTR and GFP-Bax fluorescence patterns were analyzed over time with confocal microscopy. In the beginning cells were treated with FCCP $(5 \mu \mathrm{M})$ plus the mitochondrial ATPase inhibitor, oligomycin $(2 \mu \mathrm{g} / \mathrm{ml})$. After the treatment, MTR was also present in the cytosol as a consequence of the $\Delta \Psi_{\mathrm{m}}$ collapse. Images represent data obtained from at least five different experiments

membrane-bound Bax would be higher in GFP-Bax transfected cells. This increased basal level of mitochondria-associated Bax may contribute to the early loss of $\Delta \Psi_{\mathrm{m}}$. Consistent with this notion is the observation that the loss of $\Delta \Psi_{\mathrm{m}}$ did not occur in the untransfected Cos-7 cells within the time frame examined. However, the prebound Bax represents a small population relative to the cytosolic GFP-Bax that translocates during apoptosis. In spite of the prebound Bax, our high resolution fluorescence microscopy was performed with a signal to noise ratio greater than 10 . A $3 \%$ change could be easily detected if it is continuous and cumulative, showing the high sensitivity of the method. Thus, the vast majority of GFP-Bax binding to mitochondria occurs subsequent to a decrease in $\Delta \Psi_{\mathrm{m}}$.

It is not known whether Bax forms membrane channels that allow selective ion transport and osmotic swelling of mitochondria and then leakage of the inner mitochondrial membrane, ${ }^{36,39-41}$ or if the effect of Bax is due to the direct opening of the PTP. ${ }^{30,54}$ It has been proposed that Bax binds to the PTP complex, interacts with its ANT portion and induces the permeability transition during cell death. ${ }^{30,54}$ Cyclosporine A, an inhibitor of PTP, can inhibit Baxmediated cell death. ${ }^{29,30,54}$ The PTP has been shown to be involved in the release of a mitochondrial oxidoreductase, called apoptosis inducing factor (AIF) ${ }^{20}$ and cytochrome $c^{29,30}$ However, others have found that cytochrome $c$ release does not involve the mitochondrial permeability transition. $^{6,26,34,58,59}$ Bax was not found to initiate mitochondrial swelling, one characteristic of the permeability transition $^{6,59}$ and in some experiments Bax-induced cytochrome $c$ release was not only inhibited by cyclosporine $\mathrm{A}$, but was dependent on $\mathrm{Mg}^{2+} \cdot{ }^{33}$ Intriguingly, recently Bax-induced cytochrome $c$ release was postulated to rely on its interaction with mitochondrial contact sites, independent of mitochondrial rupture. ${ }^{35}$ However, the interaction with the contact sites could lead indirectly to an activation of the PTP, since some of the components of the pore are located in the contact sites. In our experiments cyclosporine $A$ was not able to inhibit $\Delta \Psi_{\mathrm{m}}$ collapse or Bax binding to mitochondria (data not shown). It is possible that PTP opens and participates in Bax-induced apoptosis, however it does not appear to be the only trigger as Bax translocation occurs independently of PTP. Further studies using different approaches are underway to clarify this point.

The loss of $\Delta \Psi_{\mathrm{m}}$ or permeability transition alone does not induce Bax translocation into mitochondria, as the mitochondrial ATPase inhibitor, oligomycin, must be added to observe Bax redistribution. It is well known that $\Delta \Psi_{\mathrm{m}}$ is an important component of mitochondrial ATP synthesis. ${ }^{53,56,57}$ Without $\Delta \Psi_{\mathrm{m}}$ ATP synthesis stops and the ATP synthase, working in reverse, depletes cells of ATP. ${ }^{47,56,57}$ Oligomycin can be used to maintain the ATP/ADP ratio during FCCP exposure ${ }^{56}$ and prevent ATP consumption. Inhibition of the F1-Fo ATPase by oligomycin allows cell survival through glycolytic generation of ATP in the absence of the oxidative phosphorylation. ${ }^{57}$

The mitochondrial proton circuit is an important and complex pathway that influences and is influenced by $\Delta \Psi_{\mathrm{m}}$ and $\Delta \mathrm{pH}_{\mathrm{m}}$. Proton transport occurs through complexes I, II, III and IV of the ETC with F1-Fo-ATPase (complex V) 


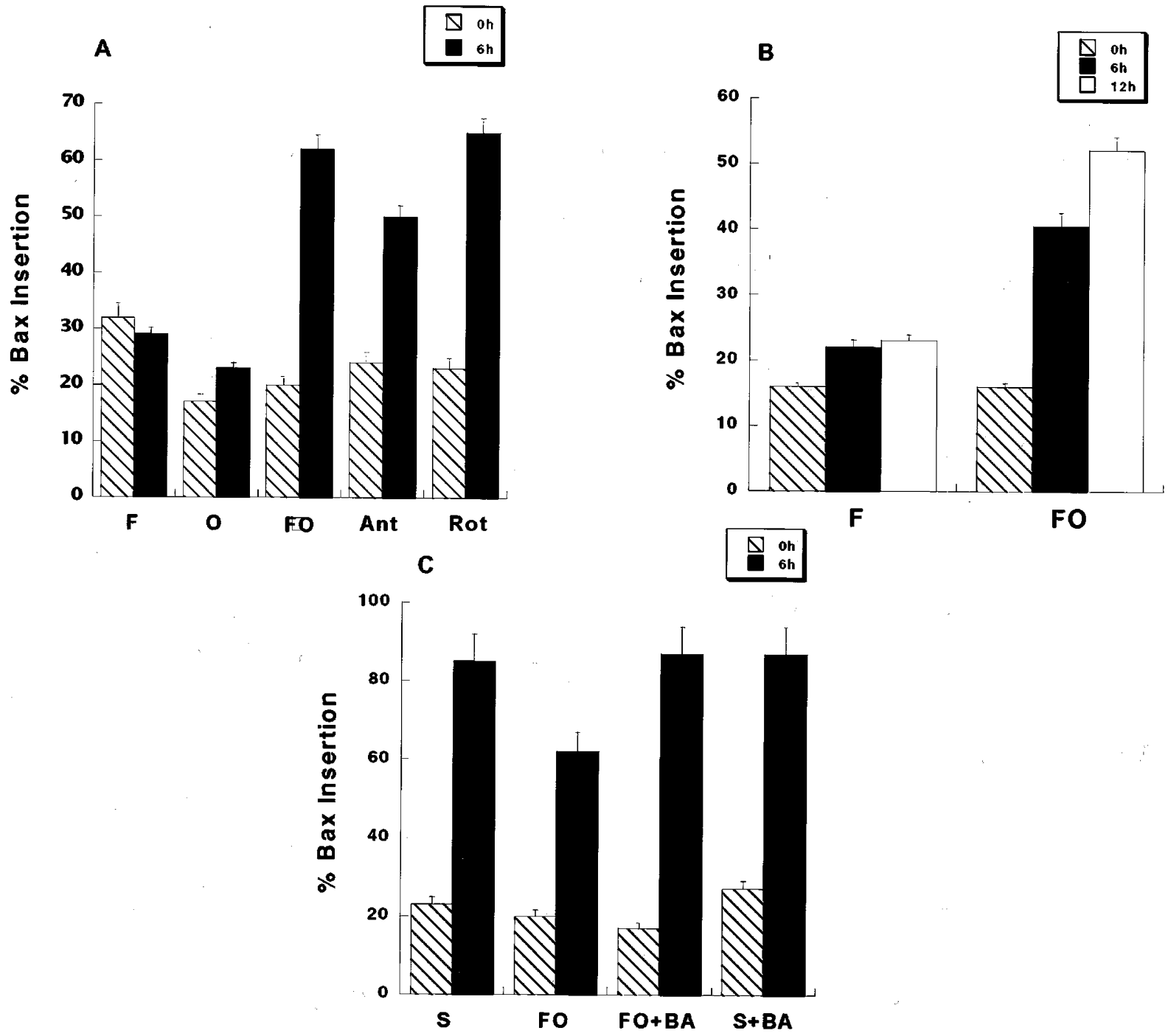

Figure 5 Effects of mitochondrial inhibitors and a calcium chelator on Bax translocation into mitochondria. (A) Cos-7 cells transfected with GFP-Bax were examined at zero $(0 \mathrm{~h})$ and $6 \mathrm{~h}$ after the treatment with $5 \mu \mathrm{M} \mathrm{FCCP} \mathrm{(F),} \mathrm{FCCP} \mathrm{plus} 2 \mu \mathrm{g} / \mathrm{ml}$ oligomycin (FO), $2 \mu \mathrm{g} / \mathrm{ml}$ oligomycin (O), $2 \mu \mathrm{M}$ antimycin (Ant) and $100 \mathrm{nM}$ rotenone (Rot). Cells treated with FO showed an increase in Bax translocation from $20-62 \%$. Cells treated with $\mathrm{F}$ or $\mathrm{O}$ alone did not show the same results. Rotenone (Rot) and antimycin (Ant) caused respectively a 40 and $25 \%$ increase in Bax translocation after $6 \mathrm{~h}$ of treatment. (B) A similar study was carried out in L929 cells. L929 cells expressing GFP-Bax were treated with FCCP or FCCP and oligomycin. Bax translocation was stimulated in cells treated with FCCP plus oligomycin after $6 \mathrm{~h}$, with a slight further increase in the number of inserted cells after $12 \mathrm{~h}$. (C) The presence of $1 \mu \mathrm{M}$ staurosporine (S) and FO significantly enhanced Bax translocation into mitochondria and after incubation with $10 \mu \mathrm{M}$ of BAPTA-AM (BA) failed to inhibit this process. Error bars represent Standard Error of the Mean (S.E.M.)

promoting reentry of protons into the mitochondrial matrix, allowing the ATP-hydrolyzing proton pump to synthesize ATP ${ }^{53,57}$ In our experiments, ETC inhibitors antimycin and rotenone, induced a collapse of $\Delta \Psi_{\mathrm{m}}$ followed by Bax translocation. In spite of the fact that the ATP-hydrolysis can be compromised by the presence of the electron transport chain inhibitors, these findings are in agreement with the observation that inhibition of the respiratory chain does not necessarily consume ATP if the glycolytic pathway is maintained. ${ }^{46,47}$ Therefore, levels of ATP are maintained, allowing Bax translocation. Presence of ATP increases the effect of Bax toxicity in yeast, suggesting that ATP is important for Bax bioactivity. ${ }^{46}$ In addition, Bax toxicity is increased in cells dependent on oxidative phosphorylation, and Bax overexpression inhibits of the respiratory chain and oxidative phosphorylation. ${ }^{48}$ While in some systems oligomycin protects cells from Bax-induced apoptosis, ${ }^{42,46,47}$ in our experiments in Bax overexpressing cells, treatment with oligomycin did not inhibit STS-induced $\Delta \Psi_{\mathrm{m}}$ loss or Bax translocation. In addition, oligomycin alone was unable to evoke a change in $\Delta \Psi_{\mathrm{m}}$ or Bax distribution, corroborating our hypothesis. Thus, it is also interesting to note that the presence of ATP maybe an important requirement during apoptotic signaling in general and this may be one of the main differences between apoptotic and necrotic cell death. ${ }^{17,19,25}$

Recent findings have shown that Bax translocation is an important step for p53-mediated apoptosis. ${ }^{60} \mathrm{Bid}$, a $\mathrm{BH} 3$ 
only protein which normally exists in the cytosol in an inactive state, moves from cytosol to mitochondria after cleavage by caspase 8 , where it induces cytochrome $c$ release. ${ }^{61}$ When cleaved by caspase 8 , Bid undergoes $\mathrm{N}$ -

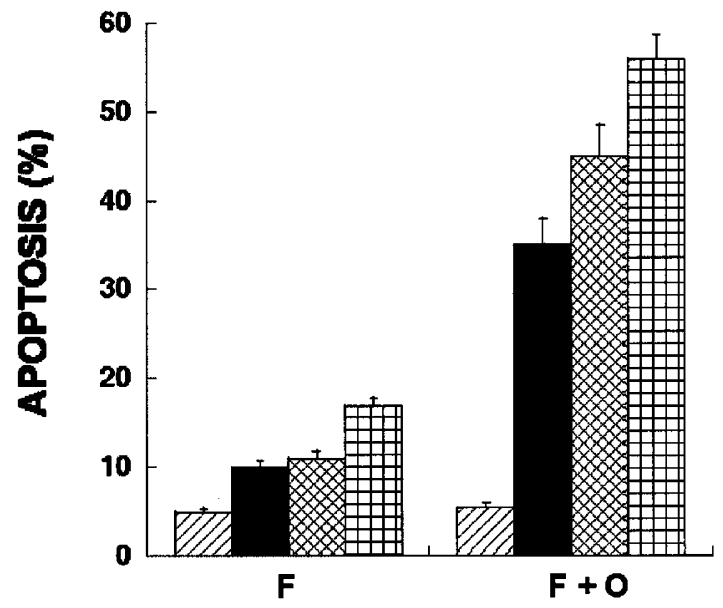

Figure 6 FCCP plus oligomycin induces apoptosis. Healthy non-transfected Cos-7 cells were treated with either FCCP $(F)$ or FCCP plus oligomycin $(\mathrm{F}+\mathrm{O})$ and the extent of cell death was determined at 0 (1st bar), 6 (2nd bar), 12 (3rd bar), and 24 (4th bar) h post-treatment using Hoechst 33342 nuclear dye staining. The percentage of apoptotic cells at different time points are shown. Error bars represent Standard Error of the Mean (S.E.M.) myristoylation which increases its ability to release cytochrome $c .^{62}$ Although there are Bax dependent and independent pathways for Bid, ${ }^{63}$ both proteins can work synergistically. ${ }^{64}$

Overexpression of Bax in cultured mammalian cell lines has been reported to promote the activation of caspase-3 and cell death. ${ }^{7,55}$ Activation of caspase- 3 has been attributed to the release of cytochrome $c$ from the damaged mitochondria during apoptosis. ${ }^{18}$ Another aspect of the sequence of events during Bax-induced apoptosis is caspase activation. Our experiments indicated that Bax translocation into mitochondria is upstream of caspase-3 activation, since the pan-caspase inhibitor zVAD-fmk is unable to inhibit $\Delta \Psi_{\mathrm{m}}$ loss and Bax translocation (not shown). ${ }^{30}$ In addition, it has been shown that caspase activation occurs after the $\Delta \Psi_{\mathrm{m}}$ loss induced by Bax microinjection. ${ }^{30}$ This is consistent with the model that the addition of exogenous Bax disrupts mitochondria resulting in the release of cytochrome $c$ and subsequent activation of caspase- 3 . $^{28}$

Taken together our results show that $\Delta \Psi_{\mathrm{m}}$ collapse precedes Bax translocation into mitochondria and Bax translocation can be induced by $\Delta \Psi_{\mathrm{m}}$ loss only if the levels of ATP are maintained. Interestingly, the prosurvival family member Bcl-2 can cause an elevation of the resting $\Delta \Psi_{\mathrm{m}}$, ${ }^{65}$ suggesting that Bax responds to a signal of mitochondrial stress associated with the rupture of the proton circuit and $\Delta \Psi_{\mathrm{m}}$ collapse. Based on our results, we propose (Figure 7)

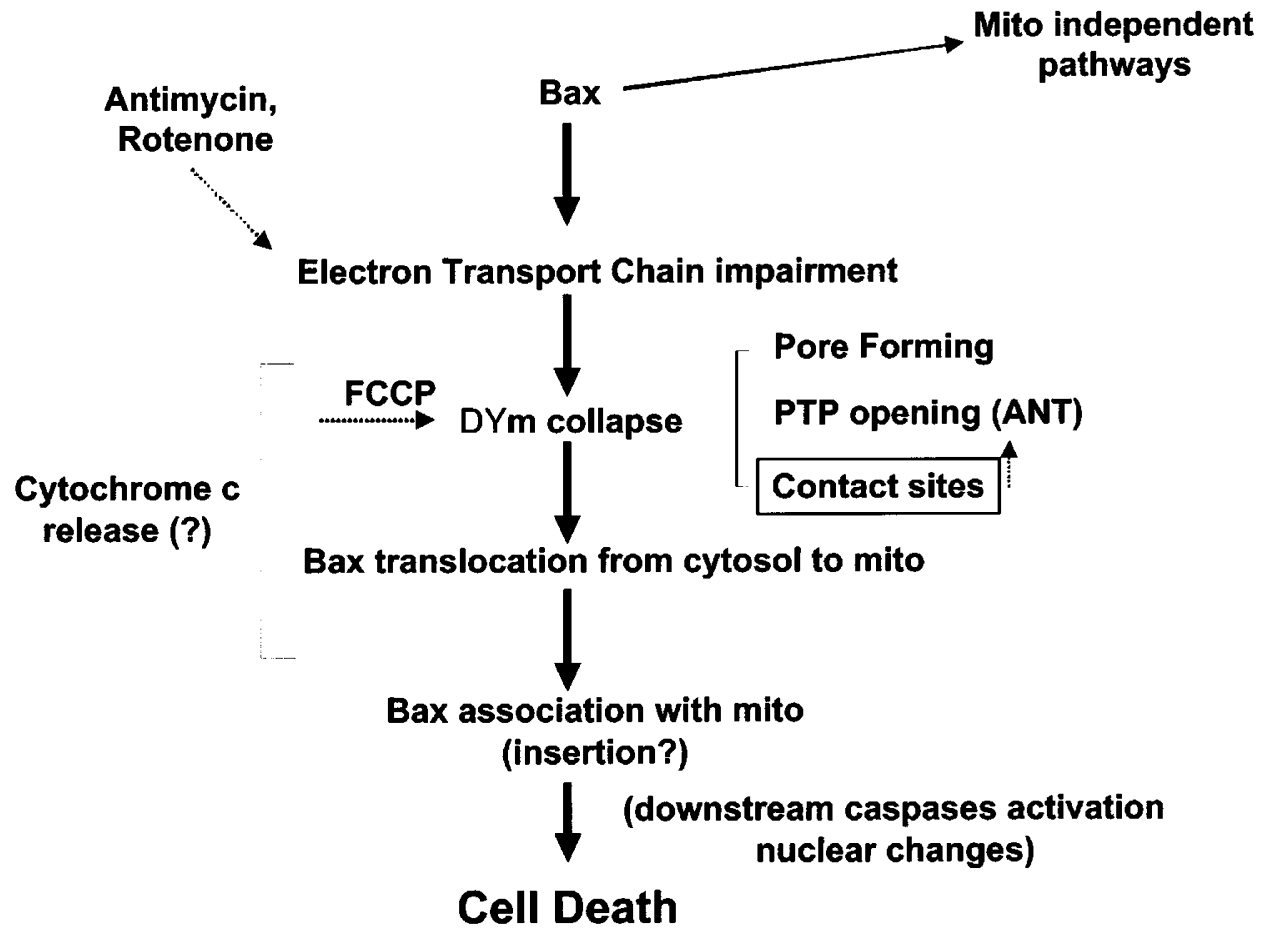

Figure 7 Schematic illustration of the mechanisms by which Bax overexpression via mitochondrial pathways induces apoptotic cell death. In this model, Bax overexpression, and other inducers of cell death through mitochondrial pathways, such as STS, FCCP, antimycin, and rotenone, cause $\Delta \Psi_{\mathrm{m}}$ disruption before measurable Bax translocation from cytosol to mitochondria. After translocation, Bax association with mitochondria occurs with possible insertion. Bax can cause $\Delta \Psi_{\mathrm{m}}$ collapse directly by rupture of the mitochondrial membrane through pore formation, by binding with ANT and opening of the PTP, or by binding at the mitochondrial contact sites. It is not clear if cytochrome $c$ release occurs before or during $\Delta \Psi_{\mathrm{m}}$ collapse. These mechanisms precede the activation of downstream caspases and late stages of apoptosis 
that Bax translocation from the cytosol to the mitochondria is caused by the collapse in $\Delta \Psi_{\mathrm{m}}$ and culminates in mitochondria disintegration, cytochrome $c$ release and thereby further triggering downstream pathways of caspase activation and the full apoptotic cascade.

\section{Materials and Methods}

\section{Cell culture and transient transfection of Cos-7 cells}

Cos-7 or L929 cells were grown in DMEM medium (Biofluids Inc., Rockville, MD, USA) supplemented with $10 \%$ fetal bovine serum, $2 \mathrm{mM}$ glutamine, $2.5 \mathrm{mM}$ sodium pyruvate, and nonessential amino acids. The cells were maintained at $37^{\circ} \mathrm{C}$ in the presence of $5 \% \mathrm{CO}_{2}$. A day prior to transfection, the cells were trypsinized and plated onto polylysine-coated cover slips as previously described ${ }^{66,67}$ placed on 6-well tissue culture plates for conventional fluorescent microscopy and on 2-well Lab-Tek chambered coverglass (Nalge Nunc, Naperville, IL, USA). Cos-7 or L929 cells were then transfected with the appropriate plasmid DNA using the protocol described by the manufacturer. Typically, $0.5 \mu \mathrm{g}$ of plasmid DNA and $4 \mu \mathrm{l}$ of LipofectAmine (Life Technologies, Gaithersburg, MD, USA) were used per coverslip. The cells were incubated for $5 \mathrm{~h}$ in the transfection mixture prior to replacement with fresh culture medium. The transfected cells were visualized by microscopy the next day.

\section{Simultaneous measurement of GFP fluorescence and $\Delta \Psi_{\mathrm{m}}$}

Cos-7 cells grown on polylysine-coated coverslips were placed in a Leiden coverslip chamber. The perfusion chamber was positioned on the stage of an inverted microscope, with fluorescence images being acquired through a microchannel plate intensifier with a CCD camera. Cells were perfused at $37^{\circ} \mathrm{C}$ in a balanced salt solution as described previously. ${ }^{66,67}$ For the simultaneous measurement of GFP fluorescence and TMRE (Tetramethylrhodamine ethyl ester, Molecular Probes Inc., Eugene, OR, USA), cells transfected with GFP-Bax were incubated with $100 \mathrm{nM}$ TMRE for $30 \mathrm{~min}$ before the experiments. GFP and TMRE fluorescence were measured using a filter set fitted with a dual-band dichroic mirror (520 and $575 \mathrm{~nm}$ ) and band-pass filters $(520$ and $600 \mathrm{~nm}, 40 \mathrm{~nm}$ full width at half-maximum transmission (Chroma Technologies, Brattelboro, VT, USA)). Cells were excited alternately through narrow band-pass excitation filters at exciting wavelengths for GFP $(485 \mathrm{~nm}, 15 \mathrm{~nm}$ full width at halfmaximum transmission) and TMRE $(530 \mathrm{~nm}, 45 \mathrm{~nm}$ full width at halfmaximum transmission). Images were acquired every $2 \mathrm{~min}$, with image intensifier gain being independently adjusted for the two fluorophores by computer control. Images were digitized and averaged using Synapse, an image acquisition and analysis software (Synergy Research Inc., Silver Spring, MD, USA). Fluorescence intensity was measured in individual mitochondria identified by TMRE staining using the region of interest $(\mathrm{ROI})$ tool. ROls were drawn around single mitochondria that did not overlap with others and the average non-zero pixel intensity within the ROls was measured and plotted against time after normalization $\left(\Delta \mathrm{F} / \mathrm{F}_{0}\right)$.

\section{Confocal microscopy}

Cos-7 cells were grown and transfected with GFP-Bax as described above in 2-well Lab-Tek chambered coverglass slides (Nalge Nunc).
After $24 \mathrm{~h}$, cells were incubated for $10 \mathrm{~min}$ with MitoTracker Red (25 nM, CMXRos, Molecular Probes Inc., Eugene, OR, USA) in microscopy buffer solution ${ }^{66}$ to label mitochondria. Cells were washed and transferred to the inverted microscope where the images were collected using a laser confocal microscope (LSM 510 microscope with a $63 \times$ objective Apochromat objective (Carl Zeiss, Thornwood, NY, USA). The 488 and $568 \mathrm{~nm}$ lines of a krypton/argon laser were used for fluorescence excitation of GFP and MitoTracker Red (MTR) respectively. The temperature of the specimen was maintained between 35 and $37^{\circ} \mathrm{C}$. Time course analyses of treated cells were carried out at 20-30 min intervals to monitor changes in GFP-Bax localization.

\section{Cell death asssay}

Apoptotic cells were quantified at different time points by staining with the Hoechst nuclear staining dye. ${ }^{10,14}$ Cells were plated in 6-well plates $24 \mathrm{~h}$ before treatment and at least three fields were counted in each of at least three wells. Results were calculated as the percentage of dead cells per total cells per field (magnification $\times 200$ ).

\section{Acknowledgements}

We thank Dr Amotz Nechushtan for helpful discussions and Drs Roger Castilho and Laurel L Haak for the critical reading of the manuscript. We thank Joan Barrick, Pat Johnson and Lynne Holtzclaw for technical assistance. SSS was supported by FAPESP (Fundação do Amparo à Pesquisa do Estado da São Paulo - Brasil) and National Institutes of Health.

\section{References}

1. Yang E and Korsmeyer SJ (1996) Molecular apoptosis: a discourse on the Bcl2 family and cell death. Blood 88: 386-401

2. Oltvai ZN, Milliman CL and Korsmeyer SJ (1993) Bcl-2 heterodimerizes in vivo with a conserved homolog, Bax, that accelerates programmed cell death. Cell 74: $609-619$

3. KrajewskiS, Krajewski M, ShabaikA, Miyashita T, Wang HG and Reed JC (1994) Immunohistochemical determination of in vivo distribution of Bax, a dominant inhibitor of Bcl-2. Am. J. Path. 145: 1323-1336

4. Knudson CM, Tung KSK, Tourtellotte WG, Brown GAJ and Korsmeyer SJ (1995) Bax-deficient mice with lymphoid hyperplasia and male germ cell death. Science 270: $96-99$

5. White FA, Keller-Peck CR, Knudson CM, Korsmeyer SJ and Snider WD (1998) Widespread elimination of naturally occurring neuronal death in Bax-deficient mice. J. Neurosci. 18: 1428-1439

6. Finucane DM, Bossy-WetzelE, Waterhouse NJ, CotterTG and Green DG(1999) Bax-induced activation and apoptosis via cytochrome $c$ release from mitochondria is inhibitable by Bcl-xL. J. Biol. Chem. 274: 2225-2233

7. Kitanaka C, Namiki T, Noguchi K, Mochizuki T, Kagaya S, Chi S, Hayashi A, Asai A, Tsujimoto $Y$ and Kuchino $Y$ (1997) Caspase-dependent apoptosis of COS-7 cells induced by Bax overexpression: differential effects of $\mathrm{Bcl}-2$ and $\mathrm{Bcl}-\mathrm{X}_{\mathrm{L}}$ on Bax-induced caspase activation and apoptosis. Oncogene 15: 1763-1772

8. Zha H, Fisk HA, Yaffe MP, Mahajan N, Herman B and Reed JC (1996) Structurefunction comparisons of the proapoptotic protein Bax in yeast and mammalian cells. Mol. Cell. Biol. 16: 6494-6508

9. Yin X-M, Oltvai ZN and Korsmeyer SJ (1994) BH1 and BH2 domains of Bcl-2 are required for inhibition of apoptosis and heterodimerization with Bax. Nature 369: $321-323$

10. Wolter KG, Hsu Y-T, Smith CL, Nechushtan A, Xi X-G and Youle RJ (1997) Movement of Bax from the cytosol to mitochondria during apoptosis. J. Cell Biol. 139: $1281-1292$ 
11. Hsu Y-T, Wolter KG and Youle RJ (1997) Cytosol-to-membrane redistribution of Bax and Bcl-X $X_{L}$ during apoptosis. Proc. Natl. Acad. Sci. USA 94: 3668-3672

12. Goping IS, Gross A, Lavoie JN, Nguyen M, Jemmerson R, Roth K, Korsmeyer S and Shore GC (1998) Regulated targeting of BAX to mitochondria. J. Cell Biol. 143: $207-215$

13. Gross A, Jockel J, Wei MC and Korsmeyer SJ (1998) Enforced dimerization of Bax results in its translocation, mitochondrial dysfunction and apoptosis. EMBO J. $17: 3878-3885$

14. Nechushtan A, Smith CL, Hsu Y-T and Youle RJ (1999) Conformation of the Bax C-terminus regulates subcellular location and cell death. EMBO J. 18: $2330-$ 2341

15. Gross A, Pilcher K, Blanchly-Dyson E, Basso E, Jockel J, Bassik MC, Korsmeyer SJ and Forte M (2000) Biochemical and genetic analysis of the mitochondrial response of yeast to Bax and Bcl-xL. Mol. Cell. Biol. 20: 3125-3136

16. Zamzami N, Marchetti P, Castedo M, Decaudin D, Macho A, Hirsch T, Susin SA, Petit PX, Mignotte B and Kroemer G (1995) Sequential reduction of mitochondrial transmembrane potential and generation of reactive oxygen species in early programmed cell death. J. Exp. Med. 182: 367-377

17. Kroemer G, Petit P, Zamzami N, Vayssiere JL and Mignotte B (1995) The biochemistry of cell death. FASEB J. 9: 1277-1287

18. Liu X, Kim CN, Yang J, Jemmerson R and Wang X (1996) Induction of apoptotic program in cell-free extracts: requirement for dATP and cytochrome c. Cell 86: $147-157$

19. Susin SA, Zamzami N, Castedo M, Hirsch T, Marchetti P, Macho A, Daugas E, Geuskens M and Kroemer G (1996) Bcl-2 inhibits the mitochondrial release of an apoptogenic protease. J. Exp. Med. 184: 1331-1341

20. Susin SA, Lorenzo HK, Zamzami N, Marzo I, Snow BE, Brothers GM, Mangion J, Jacotot E, Costantini P, Loeffler M, Larochette N, Goodlett DR, Aebersold R, Siderovski DP, Pinninger JM and Kroemer G (1999) Molecular characterization of mitochondrial apoptosis-inducing factor. Nature 397: 441-446

21. Zamzami N, Susin SA, Marchetti P, Hirsch T, Gómez-Monterrey I, Castedo M and Kroemer $\mathrm{G}$ (1996) Mitochondrial control of nuclear apoptosis. J. Exp. Med. 183: $1533-1544$

22. Castedo M, Macho A, Zamzami N, Hirsch T, Marchetti P, Uriel J and Kroemer G (1995) Mitochondrial perturbations define lymphocytes undergoing apoptotic depletion in vivo. Eur. J. Immunol. 25: 3277-3284

23. Marchetti P, Castedo M, Susin SA, Zamzami N, Hirsch T, Macho A, Haeffner A Hirsch F, Geuskens M and Kroemer G (1996) Mitochondrial permeability transition is a central coordinating event of apoptosis. J. Exp. Med. 184: 11551160

24. Heiskanen KM, Manjunatha BB, Wang H-W, Ma J and Nieminen AL (1999) Mitochondrial depolarization accompanies cytochrome $c$ release during apoptosis in PC6 cells. J. Biol. Chem. 274: 5654-5658

25. Kroemer G, Dallaporta B and Resche-Rigon M (1998) The mitochondrial death/ life regulator in apoptosis and necrosis. Ann. Rev. Physiol. 60: 619-642

26. Bossy-WetzelE, NewmeyerDD and Green DR (1998) Mitochondrial cytochrome $c$ release in apoptosis occurs upstream of DEVD-specific caspase activation and independently of mitochondrial transmembrane depolarization. EMBO J. 17: $37-49$

27. Goldstein JC, Waterhouse NJ, Juin P, Evan GI and Green DR (2000) The coordinate release of cytochrome $\mathrm{c}$ during apoptosis is rapid, complete and kinetically invariant. Nature Cell Biol. 2: 156-162

28. Jürgensmeier JM, Xie Z, Deveraux Q, Ellerby L, Bredesen D and Reed JC (1998) Bax directly induces release of cytochrome c from isolated mitochondria. Proc. Natl. Acad. Sci. USA 95: 4997-5002

29. Pastorino JG, Chen S-T, Tafani M, Snyder JW and Farber JL (1998) The overexpression of Bax produces cell death upon induction of the mitochondrial permeability transition. J. Biol. Chem. 273: 7770-7775

30. Marzo I, Brenner C, Zamzami N, Susin SA, Beutneur G, Brdiczka D, Remy R, Xie Z, Reed JC and Kroemer G (1998) The permeability transition pore complex: A target for apoptosis regulation by caspases and Bcl-2-related proteins. J. Exp. Med. 187: 1261-1271

31. Smaili SS, Hsu Y-H, Youle RJ and Russell JT (2000) Mitochondria in Ca2+ signaling and apoptosis. J. Bioenerg. Biomemb. 32: $35-45$

32. Zoratti M and Szabo I (1995) The mitochondrial permeability transition. Biochim. Biophys. Acta 1241: $139-176$

33. Eskes R, Antonsson B, Osen-Sand A, Montessuit S, Richter C, Sadoul R, Mazzei G, Nichols A and Martinou J-C (1998) Bax-induced cytochrome c release from mitochondria is independent of the permeability transition pore but highly dependent on Mg2+ ions. J. Cell Biol. 143: 217-224
34. Andreyev AY, Fahy B and Fiskum $G$ (1998) Cytochrome $c$ release from brain mitochondria is independent of the mitochondrial permeability transition. FEBS Lett. 439: 373-376

35. Doran E and Halestrap AP (2000) Cytochrome c release from isolated rat liver mitochondria can occur independently of outer-membrane rupture: possible role of contact sites. Biochem. J. 348: 343-350

36. Antonsson BF, Conti F, Ciavatta A, Montessuit S, Lewis S, Martinou I, Bernasconi L, Bernard A, Mermod J-J, Mazzei G, Maundrell K, Gambale F, Sadoul R and Martinou J-C (1997) Inhibition of Bax channel-forming activity by Bcl-2. Science 277: 370-372

37. Antonsson BS, Montessuit S, Lauper S, Eskes R and Martinou J-C (2000) Bax oligomerization is required for channel-forming activity in liposomes and to trigger cytochrome c release from mitochondria. Biochem. J. 345: 271-278

38. Hsu Y-T and Youle RJ (1997) Nonionic detergents induce dimerization among members of the Bcl-2 family. J. Biol. Chem. 272: 13829-13834

39. Basanez G, Nechushtan A, Drozhinin O, Chanturiya A, Choe E, Tutt S, Wood K, Hsu Y-T, Zimmerberg J and Youle RJ (1999) Bax, but not Bcl-xL, decreases the lifetime of planar phospholipid bilayer membranes of subnanomolar concentrations. Proc. Natl. Acad. Sci. USA 96: 5492-5497

40. Nouraini S, Six E, Matsuyama S, Krajewski S and Reed JC (2000) The putative pore-forming domain of Bax regulates mitochondrial localization and interaction with Bcl-xL. Mol. Cell. Biol. 20: 1604-1615

41. Schendel SL, Xie Z, Montal MO, Matsuyama S, Montal M and Reed JC (1997) Channel formation by antiapoptotic protein Bcl-2. Proc. Natl. Acad. Sci. USA 94 $5113-5118$

42. Borutaite V, Morkuniene R and Brown CG (2000) Nitric oxide donors, nitrosothiols and mitochondrial respiration inhibitors induce caspase activation by different mechanisms. FEBS Lett. 467: 155-159

43. Fitch ME, Chang CM and Parslow TG (2000) The BH3 domain is required for caspase-independent cell death induced by Bax and oligomycin. Cell Death Differ. 7: $338-349$

44. Mills KI, Woodgate LJ, Gilkes AF, Walsh V, Sweeney MC, Brown G and Burnett AK (1999) Inhibition of mitochondrial function in $\mathrm{HL} 60$ cells is associated with an increased apoptosis and expression of CD14. Biochem. Biophys. Res. Comm. 263: $294-300$

45. Wolvetang EJ, Johnson KL, Krauer K, Ralph SJ and Linnane AW (1994) Mitochondrial respiratory-chain inhibitors induce apoptosis. FEBS Lett. 339 $40-44$

46. Matsuyama S, Xu Q, Velours J and Reed JC (1998) Mitochondria F1-Fo-ATPase proton pump is required for function of the pro-apoptotic protein Bax in yeast and mammalian cells. Mol. Cell 1:327-336

47. Leist M, Single B, Castoldi AF, Kuhnle S and Nicotera P (1997) Intracellular adenosine triphosphate (ATP) concentration: a switch in the decision between apoptosis and necrosis. J. Exp. Med. 185: 1481-1486

48. Harris MH, Vander Heiden MG, Kron SJ and Thompson CB (2000) Role of oxidative phosphorylation in Bax toxicity. Mol. Cell. Biol. 20: 3590-3596

49. Khaled AR, Kim K, Hofmeister R, Muegge Kand Durum SK (1999) Withdrawal of IL-7 induces Bax translocation from cytosol to mitochondria through a rise in intracellular pH. Proc. Natl. Acad. Sci. 96: 14476-14481

50. Matsuyama S, Llopis J, Deveraux QL, Tsien RY and Reed JC (2000) Changes in intramitochondrial and cytosolic $\mathrm{pH}$ : early events that modulate caspase activation during apoptosis. Nature Cell Biol. 2: 318-325

51. Farkas DL, Wei M-D, Febbroriello P, Carson J-H and Loew LM (1989) Simultaneous imaging of cell and mitochondrial membrane potential. Biophys. J. 56: $1053-1069$

52. Loew LM, Carrington W, Tuft RA and Fay FS (1994) Physiological cytosolic ca2+ transients evoke concurrent mitochondrial. Proc. Natl. Acad. Sci. USA 91 $12579-12583$

53. Bernardi P, Scorrano L, Colonna R, Petronilli V and Di Lisa F (1999) Mitochondria and cell death. Mechanistic aspects and methodological issues. Eur. J. Biochem. 264: 687-701

54. Marzo I, Brenner C, Zamzami N, Jurgensmeier JM, Susin SA, Vieira HLA, Prévost M-C, Xie Z, Matsuyama S, Reed JC and Kroemer G (1998) Bax and adenine nucleotide translocator cooperate in the mitochondrial control of apoptosis. Science 281: 2027-2031

55. Xiang J, Chao DT and Korsmeyer SJ (1996) Bax-induced cell death may not require interleukin 1 beta-converting enzyme-like proteases. Proc. Natl. Acad. Sci. 93: $14559-14563$ 
56. Budd SL and Nicholls DG (1996) Mitochondrial calcium regulation and acute glutamate excitotoxicity in cultured cerebellar granule cells. J. Neurochem. 66 : 403-411

57. Nicholls DG and Budd SL (2000) Mitochondria and neuronal survival. Physiol. Rev. 80: $315-360$

58. Yang J, Liu X, Bhalla K, Kim CN, Ibrado AM, Cai J, Peng TI, Jones DP and Wang X (1997) Prevention of apoptosis by Bcl-2: release of cytochrome c from mitochondria blocked. Science 275: 1129-1132

59. Priault M, Chaudhuri B, Clow A, Camougrand N and Manon S (1999) Investigation of Bax-induced release of cytochrome $\mathrm{c}$ from yeast mitochondria. Permeability of mitochondrial membranes, role of VDAC and ATP requirement. Eur. J. Biochem. 260: 684-691

60. Deng $Y$ and Wu X (2000) Peg/Pw1 promotes p53-mediated apoptosis by inducing Bax translocation from cytosol to mitochondria. Proc. Natl. Acad. Sci. 97: $12050-12055$

61. Lutter M, Fang M, Luo X, Nishijima M, Xie WS and Wang X (2000) Cardiolipin provides specificity for targeting of tBid to mitochondria. Nat. Cell Biol. 2: $754-$ 761
62. Zha J, Wiler S, Oh KJ, Wei MC and Korsmeyer SJ (2000) Posttranslational Nmyristoylation of BID as a molecular switch for targeting mitochondria and apoptosis. Science 290: 1761-1765

63. Ruffolo SC, Brechenridge DG, Nguyen M, Goping IS, Gross A, Korsmeyer SJ, Li $\mathrm{H}$, Yuan J and Shore GC (2000) BID-dependent and BID-independent pathways for BAX insertion into mitochondria. Cell Death Differ. 7: 1101-1108

64. Kim T-H, Zhao Y, Barber MJ, Kuharsky DK and Yin X-M (2000) Bid-induced cytochrome $c$ release is mediated by a pathway independent of mitochondrial permeability transition pore and Bax. J. Biol. Chem. 275: 39474-39481

65. Kowaltowski AJ, Smaili SS, Russell JT and Fiskum G (2000) Elevation of resting mitochondrial membrane potential of neural cells by cyclosporin A, BAPTA-AM and Bcl-2. Am. J. Physiol. 279: C852-C859

66. Yagodin SV, Holtzclaw L, Sheppard CA and Russell JT (1994) Nonlinear propagation of agonist-induced cytoplasmic calcium waves in single astrocytes. J. Neurobiol. 25: 265-280

67. Smaili SS and Russel JT (1999) Permeability transition pore regulates both mitochondrial membrane potential and agonist-evoked $\mathrm{Ca} 2+$ signals in oligodendrocyte progenitors. Cell Calcium 26: 121-130 